\title{
PRODUÇÃO DE SAÚDE: EXPERIÊNCIAS NA REDE DE ATENÇÃO PSICOSSOCIAL
}

\section{ARTIGO ORIGINAL}

SOUZA, Luiz Augusto de Paula ${ }^{1}$

MENDES, Vera Lucia Ferreira ${ }^{2}$

COSTA, Rogério da ${ }^{3}$

MAHFUZ, Marcela Saddi 4

OLIVEIRA, Bianca Lima de ${ }^{5}$

FRANÇOIS, Amana Borgo ${ }^{6}$

MIRANDA, Davi Cruz ${ }^{7}$

SOUZA, Luiz Augusto de Paula. Et al. Produção de saúde: experiências na Rede de Atenção Psicossocial. Revista Científica Multidisciplinar Núcleo do Conhecimento. Ano 04, Ed. 12, Vol. 08, pp. 139-156. Dezembro de 2019. ISSN: 2448-

${ }^{1}$ Doutor em Psicologia Clínica e professor titular da Faculdade de Ciências Humanas e da Saúde da PUC-SP.

2 Doutora em Psicologia Clínica e professora doutora da Faculdade de Ciências Humanas e da Saúde da PUC-SP.

${ }^{3}$ Doutor em Filosofia e professor doutor do Programa de Estudos, Pós Graduados em Comunicação e Semiótica da PUC-SP.

${ }^{4}$ Psicóloga pela PUC-SP.

${ }^{5}$ Psicóloga pela PUC-SP.

${ }^{6}$ Psicóloga pela PUC-SP.

${ }^{7}$ Psicólogo pela PUC-SP. 
0959,

Link

de

acesso: https://www.nucleodoconhecimento.com.br/psicologia/producao-de-saude

\section{RESUMO}

O artigo apresenta um estudo documental sobre produção videográfica realizada pelos participantes do projeto Redes de Produção de Saúde na perspectiva da Inteligência Coletiva, da Escola Municipal de Saúde, Programa Rede Sampa - Saúde Mental Paulistana. O objetivo do trabalho é analisar a produção de saúde e o trabalho em rede em experiências de efetivação do cuidado à saúde registradas em vídeos de mídia tática por trabalhadores e gestores da Rede de Atenção Psicossocial Paulistana (RAPS paulistana). Os resultados do estudo mostram diversas formas de relação entre serviços de saúde mental, projetos e ações intersetoriais e comunitárias na cidade de São Paulo, bem como revela potencialidades de produção e qualificação de processos de cuidado em saúde mental pela RAPS paulistana, principalmente a partir da intersecção com os usuários dos serviços de saúde e com os contextos concretos nos quais eles vivem.

Palavras-chave: produção videográfica, produção de saúde, saúde mental.

\section{INTRODUÇÃO}

Este artigo analisa os resultados de uma pesquisa cujo objeto foi, em certa medida, outra pesquisa. Explica-se. De junho de 2016 até abril de 2017 realizou-se, na cidade de São Paulo, um projeto de intervenção promovido pelo Rede Sampa - instância de Educação Permanente da Secretaria Municipal de Saúde de São Paulo.

O projeto consistiu numa intervenção formativa para gestores e trabalhadores da Rede de Atenção Psicossocial Paulistana (RAPS paulistana), realizada por meio de pesquisa cartográfica destinada a identificar e examinar "pontos de produção de saúde" na cidade.

A referência aos "pontos de produção" tem a ver com a inovadora ideia de "pontos de cultura" da política pública lançada pelo Ministério da Cultura em 2004, com objetivo 
de apoiar projetos baseados em tradições e saberes de cada comunidade. Muito esquematicamente: por meio dos pontos de cultura, a produção cultural foi assumida, reconhecida e valorizada em sua multiplicidade e em função da vastíssima e heterogênea criação cultural brasileira, nos mais variados recantos do país, gêneros culturais e segmentos sociais, a partir dos quais a riqueza cultural é gestada e se expressa, para além do mainstream e do mercado cultural.

Essa ideia, levada ao campo da saúde, quer apontar para o fato de que a saúde e os processos de saúde/doença, além de estarem vinculados aos serviços de saúde e digamos assim - às tecnologias e produtos do setor, também e principalmente são produzidos pelas relações entre as pessoas e delas com as informações, conhecimentos, valores, hábitos, costumes e formas decorrentes de lidar com o meioambiente natural e social dos quais fazem parte.

Em outras palavras, os processos que mantém e promovem a saúde, os que enfrentam as doenças e os sofrimentos (e às vezes também fazem adoecer iatrogênese) não respondem, nem estão ligados apenas a conhecimentos sistemáticos, práticas profissionais, ambientes e dispositivos técnicos, tecnológicos e científicos, mas também aos modos de vida e às políticas de existência, que as pessoas, grupos e segmentos sociais constituem ao longo do tempo e sob condições sociais e sanitárias determinadas (políticas, econômicas, culturais, históricas...). Essa consideração define, inclusive, o sentido do título do artigo: a condição biológica da saúde é sobre determinada pela produção social e histórica que a define.

No interior desse universo é que se pode falar em produção de saúde, e pensá-la como uma produção coletiva, não apenas porquê envolve relações entre pessoas, grupos e segmentos sociais, mas porque essas relações conformam coletivos de forças subjetivas, cognitivas, sociais, políticas, etc.

A cartografia dos "pontos de produção de saúde" buscou identificar perspectivas implicadas com princípios do Sistema Único de Saúde (SUS) na produção de saúde mental na cidade de São Paulo, sobretudo o trabalho em rede na saúde, tanto em experiências ligadas diretamente às práticas dos serviços da RAPS, quanto em 
experiências intersetoriais e/ou comunitárias. Em todos os casos, desde que os trabalhadores e gestores da Saúde Mental envolvidos reconhecessem nessas perspectivas potências de produção de saúde.

A peculiaridade da intervenção proposta foi que as cartografias dos "pontos de produção de saúde" tinham que ser realizadas por meio de narrativas audiovisuais no gênero mídia tática: intervenção direta no debate público e uso autoral das mídias digitais, por meio da apropriação de meios de produção e de difusão midiáticos - nos moldes do "faça você mesmo" - sem a obrigação de produção e/ou mediação da mídia corporativa ou institucional (CLINIO, 2013).

Tal acervo documental foi tomado como objeto de investigação, analisando as narrativas audiovisuais que, registrando experiências concretas nos territórios de saúde, permitiram a reflexão sobre aspectos e dimensões conceituais de proposições do Sistema Único de Saúde (SUS), que sustentam a produção de saúde no trabalho em rede para efetuação do cuidado em saúde. Os conceitos de trabalho em rede, clínica ampliada e escuta comparecem intensamente nas narrativas audiovisuais analisadas e, por isso, requerem ainda algumas considerações, para que fiquem mais claras a análise e a discussão do acervo videográfico, que serão realizadas mais adiante.

A lógica do trabalho em rede foi proposta pelo SUS como forma de avançar, principalmente, na construção da integralidade em saúde, buscando tornar os cuidados mais qualificados e resolutivos, bem como menos fragmentados e estritamente disciplinares, ampliando as possibilidades de compreensão dos determinantes multifacetados do processo saúde/doença, e fomentando gestão e práticas de saúde interdisciplinares, capazes de integrar saberes disciplinares e de produzir intervenções consistentes em relação à complexidade dos fatores que constituem os modos de vida e suas relações com a saúde humana, as formas de adoecimento, as doenças e os processos de cuidado em saúde.

Nesse sentido, a Portaria n. 4279, de 30 de Dezembro de 2010, define Rede de Atenção à Saúde (RAS) como: 
(...) arranjos organizativos de ações e serviços de saúde, de diferentes densidades tecnológicas, que integradas por meio de sistemas de apoio técnico, logístico e de gestão, buscam garantir a integralidade do cuidado. (...) Caracteriza-se pela formação de relações horizontais entre os pontos de atenção com o centro de comunicação na Atenção Primária à Saúde (APS), pela centralidade nas necessidades em saúde de uma população, pela responsabilização na atenção contínua e integral, pelo cuidado multiprofissional, pelo compartilhamento de objetivos e compromissos com os resultados sanitários e econômicos.

O cuidado é, em última instância, um dos objetivos centrais e estratégicos de qualquer sistema de saúde. Garantir a integralidade do cuidado, como pretende a RAS, sugere uma concepção ampliada da clínica e, nela, também escuta à alteridade, ao outro (usuário, profissional, gestor, contexto sanitário e social), no sentido de requalificar a tradição estritamente disciplinar, centrada na doença e na relação médico-paciente, que caracterizaram e ainda predominam nos cuidados clínicos realizados na saúde pública.

Pensar uma clínica ampliada convida a um horizonte mais largo, no qual o objeto de trabalho seja resignificado para que os especialistas se responsabilizem por sujeitos e condições de vida e saúde concretos, não por saberes disciplinares estritos (MINISTÉRIO DA SAÚDE, 2009).

Significa dizer que a clínica ampliada busca construir sínteses singulares entre os saberes disciplinares, tensionando os limites de cada matriz disciplinar para colocar em primeiro plano a situação real do trabalho em saúde, vivida a cada instante por sujeitos e contextos sanitários reais. Isso não significa desvalorizar abordagens disciplinares, ao contrário, trata-se de coloca-las em outra chave de compreensão: integrar várias abordagens para possibilitar um manejo eficaz da complexidade do trabalho em saúde.

Assumir o trabalho em saúde a partir do conceito de clínica ampliada é colocar em análise e mitigar, na prática, a fragmentação do processo de trabalho e, por isso, criar contextos favoráveis para que se possa problematizar um certo especialismo ainda dominante no campo da saúde, em favor do trabalho em rede e de práticas de saúde 
não restritas à doença ou a núcleos profissionais específicos (CURVO, MATOS, SOUZA e PAZ, 2018).

Em síntese, o trabalho em rede buscado pela RAS quer garantir a integralidade do cuidado e, para tanto, necessita da clínica ampliada e nela da escuta clínica, como condição para potencializar a abertura do campo da saúde à vida, tal como ela acontece nos territórios sob condições multivariadas (SAMUDIO, 2017). A análise dos vídeos de mídia tática, que constituíram o acervo documental aqui pesquisado, apontam para tais perspectivas em experiências cotidianas da RAPS: efeitos concretos do trabalho em rede se dão a ver e descortinam potencialidades da ação coletiva e das práticas colaborativas na produção de saúde.

\section{MÉTODO}

A pesquisa é de natureza qualitativa, caracterizada como estudo documental do acervo de trinta e um (31) vídeos de mídia tática elaborados por trabalhadores e gestores da RAPS-Paulistana durante a intervenção formativa Redes de Produção de Saúde na Perspectiva da Inteligência Coletiva, promovida pela Secretaria Municipal de Saúde no âmbito da Escola Municipal de Saúde (Programa Rede Sampa), no período de junho de 2016 a abril de 2017.

Segundo Gil (2008), a pesquisa documental tem semelhanças significativas com a pesquisa bibliográfica, diferindo em função da natureza das fontes: na pesquisa bibliográfica as fontes são escritas, necessariamente secundárias e de diversos autores; na pesquisa documental, as fontes geralmente não receberam ainda tratamento analítico: documentos de arquivos públicos ou privados; cartas; diários; fotografias; filmes; gravações em áudio, diários, memorandos, ofícios, atas de reunião, e-mails, etc. No presente estudo, os documentos, como mencionado, são filmes ou, mais especificamente, vídeos produzidos no gênero mídia tática. 


\section{COLETA E ANÁLISE DOS DADOS}

Antes de trabalhar com o acervo de vídeos, dois dos coordenadores e uma tutora da intervenção formativa que deu origem aos vídeos e que participaram da presente pesquisa, esclareceram as condições de produção do material videográfico em questão. Em síntese, entre trabalhadores e gestores da RAPS paulistana foram noventa e seis os participantes do processo, divididos em duas turmas. A intervenção durou, aproximadamente, dois meses e meio com cada turma, contando com encontros presenciais de formação e preparação para construção das narrativas audiovisuais, trabalho de campo para as filmagens e atividade de edição e montagem dos conteúdos captados. Os processos de trabalho das turmas também foram registrados em vídeo, por meio de dois documentários disponíveis em: https://youtu.be/P0EM8qPuk50 e https://youtu.be/9D8izhEeYks .

Os encontros presenciais consistiram em formação conceitual introdutória, especialmente sobre os conceitos de rede, inteligência coletiva, trabalho em rede na saúde, comunicação e saúde, mídia tática e técnicas básicas de vídeo (roteiro, captação, edição, montagem e publicação na WEB). Em seguida, os encontros foram destinados ao acompanhamento e orientação (técnica e de conteúdo) da elaboração dos vídeos.

Para o trabalho de mídia tática, os participantes organizaram-se em grupos e produziram um total de quarenta e um vídeos, dos quais trinta e um estão disponíveis no Youtube (dez vídeos não foram tornados públicos por razões de sigilo de situações e/ou pacientes, bem como por escolha dos autores) e constituem o acervo de dados documentais da pesquisa, com diversificadas experiências e reflexões relacionadas à produção de saúde no interior do trabalho em rede no campo da saúde mental na cidade de São Paulo.

Após assistir, registrar, diagramar e codificar todos os vídeos por temáticas e conteúdos (abordagens e conceitos utilizados nas narrativas), a análise dos dados levou em consideração os aspectos e dimensões recorrentes no material para definir a abordagem a ser utilizada (ANA e LEMOS, 2018). 
Os conteúdos dos vídeos deixam ver como seus realizadores pensam e narram as situações que escolheram como capazes de expressar experiências concretas de produção de saúde. Certos elementos conceituais ligados ao SUS e relacionados à Rede de Atenção à Saúde (RAS), destacam-se nas narrativas audiovisuais ou mesmo inspiram sua construção, são eles: trabalho em rede, produção de saúde, clínica ampliada e escuta aos sujeitos e à realidade sanitária. Por isso, essas referências foram apresentadas na introdução do artigo, em rápida revisão da literatura para facilitar a compreensão dos principais aspectos conceituais envolvidos nos vídeos.

Por seu lado, as categorias relativas à natureza das experiências de produção de saúde foram três, derivadas dos tipos de dispositivos cartografados como pontos de produção de saúde na cidade de São Paulo: - vídeos de experiências que focaram, predominantemente, o cuidado em rede em ações dos próprios serviços de saúde da RAPS; - experiências que priorizaram mais fortemente ações intersetoriais (saúde e cultura, saúde e esporte, saúde e lazer, saúde e trabalho, etc.); e vídeos com experiências cujo foco principal foram ações, intervenções ou projetos da comunidade no ambiente urbano da cidade de São Paulo (projetos culturais, intervenções artísticas, ações de uso do espaço urbano e de afirmação do direito à cidade, e reflexões de usuários dos serviços da RAPS sobre suas vidas e processos de saúde/doença).

A discussão do material realiza uma leitura de conjunto do acervo videográfico e, na sequência, volta-se a cada uma das categorias referidas, destacando os vídeos mais representativos dos aspectos, dimensões e sentidos ligados à produção de saúde.

\section{RESULTADOS E DISCUSSÃO}

Ao observar as experiências abordadas nos vídeos de mídia tática, o que se pretendeu foi extrair das narrativas as percepções dos trabalhadores/autores sobre produção de saúde, bem como as concepções e bases conceituais que as sustentam.

Os aspectos e as dimensões considerados pelos autores dos vídeos como capazes de produzir saúde leva à compreensão do caráter multifacetado da produção de 
saúde, que implica, entre outras coisas: promoção de cuidado, prevenção de doenças, produção de bem estar, de modos de vida e de sociabilidades, que ampliem a experiência individual e coletiva dos sujeitos em suas relações com suas vidas, seus corpos e seus territórios existenciais, digamos assim, geográficos e subjetivos.

$\mathrm{Na}$ atualidade, é possível afirmar que existe consenso em relação ao fato de que saúde não é apenas ausência de doenças associada à condições ambientais sem risco ou de baixo risco aos agravos de saúde. Diferentemente, a saúde é dinamicamente produzida no bojo de um conjunto complexo e multivariado de fatores e variáveis: biológicos, ambientais, sociais, culturais, políticos e econômicos, que variam ao longo do tempo tanto para as pessoas tomadas individualmente, quanto para as sociedades (SOUZA e MENDES, 2009; TEIXEIRA, 2004 e 2105).

Se a saúde é produzida nas relações entre fatores e dimensões variados e heterogêneos, os vídeos analisados, refletindo sobre experiências locais de produção de saúde, foram capazes de identificar dinamismos dessa produção? Se o fizeram, a partir de quais perspectivas e operadores conceituais ou das políticas públicas do SUS?

As respostas a essas questões, por um lado, já foram anunciadas na revisão da literatura, uma vez que foi frequente, ou quase unânime, a utilização (direta ou indireta) de perspectivas da clínica ampliada, do trabalho em rede, da escuta e, às vezes, também das noções de promoção de saúde e de prevenção de doenças na escolha da experiência a ser filmada, como também nas narrativas que os vídeos lograram construir. Por outro lado, a variedade de experiências filmadas demonstra, de fato, o caráter dinâmico e plural da produção de saúde.

É exatamente nessa medida que um olhar mais geral sobre o conjunto dos vídeos permite ver a produção de saúde aparecendo como: leitura e envolvimento com a realidade dos territórios de saúde; convívio entre diferenças de realidades, saberes e formações profissionais; apropriação de espaços públicos como forma de exercer o direito à saúde; formas diversas de elaboração da vida individual e coletiva, o que aparece como central à saúde mental das pessoas e coletividades; realização de 
práticas sociais consideradas saudáveis (atividades físicas regulares, manifestações artísticas, culturais e políticas, etc.); geração de emprego e renda como forma de inclusão e circulação social, o que é também pensado como produtor de saúde.

Além disso, os vídeos deixam transparecer ou, em certos casos, dizem explicitamente que se abrir a essas formas de produção de saúde exige um conceito ampliado de clínica, que não se restrinja à circunscrição da doença e à díade terapeuta/paciente, e que permita a transversalidade entre disciplinas, tecnologias e serviços de saúde. Também fica razoavelmente claro que a condição de possibilidade para o exercício da clínica ampliada é a escuta, como disponibilidade e formação suficientes para se abrir e estar em condições de compreender e acolher as variáveis que estiverem incidindo numa experiência de produção de saúde, nos casos individuais e/ou coletivos que exigirem os cuidados dos serviços de saúde.

Quando é assim, as práticas de saúde ampliam sua perspectiva clínica, ampliam também as relações dos serviços de saúde com a comunidade e a instigam a se envolver e a participar da produção de saúde e dos serviços de saúde nos contextos sociais em que vivem.

A relevância da clínica ampliada à produção de saúde se dá nos vídeos, então, pelo fato de procurarem integrar o cuidado a partir da construção conjunta, horizontal, entre saberes, práticas, modos de vida e de socialização, tensionando as matrizes disciplinares para que a experiência vivida dos usuários da RAPS paulistana seja prioritária na organização do trabalho em saúde.

Vários vídeos pesquisados tem temática em comum: - narrativas que enfatizam o uso e a apropriação de espaços públicos por pessoas e grupos, ou seja, narrativas que consideram o exercício do direito à cidade como forma de produção de saúde; narrativas que identificam equipamentos ou projetos de saúde e cultura como espaços para manifestações e ações da comunidade, o que fomenta a proximidade, a implicação e o usos de equipamentos públicos e projetos culturais como forma, digamos assim, estruturadas de produção de saúde pela comunidade; - e, por fim, narrativas que tomam o corpo como "ponto de produção de saúde", não o corpo 
estritamente biológico, mas o corpo habitado pela história de vida, pelos encontros, pelas experiências subjetivas constitucionais (inclusive aquelas que fazem adoecer).

\section{PRODUÇÃO DE SAÚDE EM SERVIÇOS DA RAPS}

A narrativa dos vídeos nesta categoria gira, principalmente, em torno de como os profissionais enxergam suas práticas, se veem como produtores de saúde e como os usuários percebem (ou não) sua inserção nessa produção. É ideia recorrente a necessidade dos profissionais em trocar saberes e se articular no atendimento aos pacientes que, por sua vez, precisam protagonizar seus processos de saúde.

A sustentável leveza do ser[8] e Você produz saúde?[9] são vídeos que ilustram o olhar dos profissionais, que se movimenta entre o mundo interno e o externo, pensando as ações de saúde não só como prestação de serviço, mas como relação, trama afetiva. Isso remete à ideia de que a rede precisa ser viva, isto é, aberta ao movimento, à dinâmica e às transformações da vida pessoal e social: para mudar é necessário ser tocado pelo outro.

É possível perceber nas falas de profissionais entrevistados em certos vídeos, que eles estão voltados à qualidade da escuta clínica e do acolhimento que oferecem, como espécies de chaves para produzir saúde. Um dos vídeos que ilustra isso é o Reunião de redes de saberes[10]. Nele, a transdisciplinaridade é foco constante, considerada indispensável para garantir que o usuário seja recebido em um ambiente qualificado e capaz de ouvir, acolher e atender suas demandas.

Em busca da integralidade do cuidado, as discussões nos vídeos não se restringem aos profissionais, uma vez que a produção de saúde se dá a partir de potencialidades, muitas vezes, externas aos serviços. A devolutiva dos usuários e sua participação ativa, quando possível, é parte essencial da criação de dispositivos que acolherão/atenderão as demandas da população.

A dimensão da participação dos usuários é explícita nos videos Desinsti[11], UA Jabaquara[12] e Grupo Antitabagismo UBS Ilza W. Hutzler[13]. Nas falas dos usuários 
identifica-se impactos e mudanças, que as ações de saúde se mostraram capazes de gerar.

Um vídeo que, em alguma medida, vai mais fundo no pensar o sujeito em seu processo de saúde é o Pontos de produção de saúde mental no centro de população em situação de rua. Ali, vê-se estratégias coletivas, que ajudam a promover a autonomia dos sujeitos envolvidos. O vídeo pensa a situação da população de rua, que traz demandas de saúde muito específicas, evidenciando a necessidade da clínica ampliada: em um contexto de rua, as ações coletivas são ainda mais impactantes e representam a luta por direitos, incluindo o direito à saúde.

No vídeo $O$ que é acessibilidade para você?[14] tem-se um diálogo que pensa a acessibilidade como aspecto importante do direito à cidade. Se a tendência imediata ou de senso-comum sobre acessibilidade remete à remoção de barreiras arquitetônicas impostas às pessoas com deficiência física, é preciso discutir também barreiras comunicacionais e atitudinais enfrentadas pelas pessoas com deficiência visual, auditiva e intelectual, assim como outros grupos vulneráveis, por exemplo, população de rua e LGBTQI+.

Em alguma medida, todos os vídeos analisados nesta categoria vão ao encontro do trabalho em rede como uma das principais frentes de ação dos profissionais da RAPS. O que se entende por produção de saúde parece passar por aquilo que, de alguma forma, responde às demandas dos usuários e da comunidade no território, o que inclui cuidar da saúde dos próprios profissionais; dimensões que somente são possíveis sob uma concepção ampliada da clínica, o que, por tudo que foi dito até aqui, implica o trabalho em rede na saúde.

\section{A COMUNIDADE PRODUZ SAÚDE}

Nos vídeos Território Rua[15], Sampa Cinza[16], Vídeo Convite Território Penha[17], Manifesta na Cidade[18], Paulista aberta de Domingo[19] e Ocupaí[20], as narrativas põem em contato com experiências compartilhadas em espaços públicos da cidade de São Paulo; experiências de apropriação da cidade, de uso de bens públicos para 
geração do bem comum, do convívio entre diferentes e diferenças em ações políticas, esportivas, de lazer e de arte urbana.

Teixeira (2004) aponta a necessidade de um esforço coletivo para produção de saúde, para além daquele dos trabalhadores da saúde. Os vídeos nesta categoria indicam possibilidades concretas de materialização de esforços em ações e projetos da própria comunidade, assumindo a produção de saúde como experiência, simultaneamente, ético-política e conversacional, que coloca em relação de convivência diferenças entre pessoas, grupos e segmentos sociais.

Os vídeos Horta das Corujas[21], llú Obá de Min[22], Casa do Povo[23], SUSDANCE[24] e Ponto de Geração de Renda do Butantã[25], embora com temáticas diversas, também alinham-se como experiências de produção de saúde da comunidade. O Horta das Corujas exibe uma atividade comunitária que usa um bem público (horta comunitária na Praça das Corujas, no bairro da Vila Madalena) para gerar um "em comum", produzindo vínculos entre os diferentes que ali circulam (inclusive pacientes do CAPS da região). Projeto comunitário apoiado pela prefeitura municipal e potente para produzir diálogo e convívio entre diferenças, ou seja, a ação coletiva mediada pela horta comunitária, além do próprio trabalho de plantar e de colher segundo regras comunitárias pactuadas, faz emergir um sentido de pertença e de participação social solidária, com potencial de produção de saúde.

O grupo llú Obá de Min, no qual as músicas criadas e tocadas por mulheres percussionistas promovem encontros entre elas e com o grande público, que assiste aos espetáculos do grupo, aposta no empoderamento das mulheres como potência que também produz saúde. Mulheres de faixas etárias distintas, extrações sociais também relativamente variadas, produzem redes afetivas entre elas e com seu público. Um "comum" musical, social e de luta social das mulheres em torno de questões de classe, de gênero e de etnia organiza-se a partir do grupo, que já é patrimônio cultural da cidade.

Os vídeos llú Obá de Min, Casa do Povo, SUSDANCE e Ponto de Geração de Renda do Butantã são experiências de produção de saúde mental, na medida em que ativam 
a elaboração subjetiva e social, bem como ampliam formas de sociabilidade, de integração economicamente produtiva (Ponto de geração de renda do Butantã) e de usufruto do corpo e da mente.

Os dois primeiros vídeos citados (llú Obá de Min e Casa do Povo) são produções próprias da comunidade, enquanto o vídeo SUSDANCE corresponde a um projeto da área da saúde que, no entanto, parte da articulação com um projeto de jovens da comunidade: grupos de street dancing. Esse encontro cria a experiência do SUSDANCE.

O SUSDANCE amplia a perspectiva da clínica e ativa relações da comunidade com os respectivos territórios e com os serviços de saúde, colocando lado a lado adolescentes do street dancing com pacientes das unidades de saúde. Os adolescentes ensinam, coreografam e participam junto nos shows do SUSDANCE, o que gera integração social dos pacientes, aproxima os adolescentes (faixa etária que adere pouco às ações de saúde que lhe é destinada, de prevenção de DSTs e de gravidez na adolescência, por exemplo), combate a discriminação e o preconceito social contra pacientes com transtornos mentais ao inseri-los na produção cultural popular e de jovens.

As apresentações do SUSDANCE em vias públicas ou em teatros fazem sucesso e já foram noticiadas pela mídia (vídeos do SUSDANCE são facilmente encontrados na internet). A inclusão social e cultural é, certamente, um poderoso dispositivo de produção de saúde e, nela, de cuidado clínico (ampliado) aos pacientes da saúde mental.

O terceiro e último grupo temático de vídeos desta categoria diz respeito ao corpo como "território" produtor de saúde. Os vídeos aqui são dois: Experimentação: arte Interface com a saúde[26] e Livro Humano[27]. Por meio de uma linguagem poética, constitui-se uma experiência pessoal potente de apropriação do próprio corpo e de produção de subjetividade, advindas de processos terapêuticos levados a cabo em serviços da RAPS paulistana, o que pede escuta e concepção ampliada de clínica por parte dos profissionais de saúde, para que seja possível estabelecer um cuidado 
aberto e integral, por meio de uma relação elaborativa desses sujeitos sobre suas histórias de vida, de sofrimento psíquico e de cura, fazendo de seus corpos e das relações significativas e saudáveis, que estabelecem com o outro (terapeuta, familiares, amigos, etc.), verdadeiros pontos de produção de saúde.

\section{INTERSETORIALIDADE NA PRODUÇÃO DE SAÚDE}

Ao todo, cinco vídeos foram classificados como intersetoriais. Na maioria, essas produções mostram atividades de lazer, esporte e entretenimento, destacando a atividade física, a sociabilidade, a integração e a inclusão social como formas de se alcançar bem estar biopsicossocial e, por isso, de produzir saúde. Os vídeos trazem entrevistas com profissionais e usuários participantes das atividades intersetoriais e momentos das atividades em questão.

O vídeo Casa Amarela - Santo Amaro[28] mostra um conjunto de atividades abertas ao público e realizadas por uma ocupação de artistas transformada no Centro Cultural Casa Amarela. Foi identificada como ponto de produção de saúde por abrigar experiências culturais e comunitárias capazes de promover sociabilidade, conhecimentos e bem-estar social.

Copa da Inclusão[29], vídeo no qual as atividades de esporte e lazer são protagonistas, por meio de em trabalho de inclusão promovido por equipamentos da saúde (Centro de Atenção Psicossocial - CAPS; Centro de Convivência e Cooperativa - CECCOs; Núcleo de Apoio à Saúde da Família - NASF; etc.) em parceria com o Serviço Social do Comércio (SESC/SP). A ideia básica aqui é a de que o bem estar individual e coletivo, a partir da inclusão social, do esporte e do lazer, além da possibilidade de uso e circulação em espaços públicos, são produtores de saúde.

Entrevistas sobre atividades e experiências de saúde no território Jaçanã/Tremembé compõem o vídeo Território Jaçanã - Tremembé[30], com interfaces na arte, na cultura e no esporte. As autoras entendem como produção de saúde a união entre equipamentos de saúde para proporcionar opções de cuidado e de lazer aos usuários; 
pensam a saúde também como circulação e uso da cidade pelos usuários dos serviços de saúde mental da região.

Entre Oceanos[31] é um vídeo que consiste em entrevista com o gestor do CAPSi Mooca e com a enfermeira da UBS Mooca I sobre a situação de refugiados Sírios, que chegaram ao Brasil fugindo da guerra em seu país. O vídeo tematiza as necessidades de saúde da população refugiada, falando das ações setoriais e intersetoriais pensadas pelos trabalhadores da saúde para acolher esse grupo populacional: elaboração e retirada de documentos pessoais; regularização da situação de refugiado; cadastro no SUS; elaboração de cartografia e de itinerários da região para os refugiados se orientarem; entre outros.

O vídeo Entrelaçando rendas e rede[32], apresenta o trabalho em rede por meio de várias atividades intersetoriais: produção dos usuários do Cecco Mooca; produção de redes entre os Ceccos da região sudeste da Cidade de São Paulo; cursos de economia solidária; confecção de produtos pelos usuários de Pontos de Economia Solidária para venda no Congresso Brasileiro de Saúde Mental e em outros eventos; entre outros. O trabalho é visto como forma de materializar perspectivas da clínica ampliada na produção de saúde, por meio da estruturação da rede de relações e de produção entre diversos setores e serviços da prefeitura de São Paulo.

Em todos os vídeos desta categoria, a premissa para a produção de saúde foi promover escuta às reais necessidades da população usuária dos serviços, o que justificaria, inclusive, a construção de iniciativas intersetoriais para atendê-las. No geral, há consenso sobre o fato de que saúde vai além de receber atendimento especializado e contempla, entre outras coisas, a realização de atividades que promovam bem estar, inclusão e integração social.

No entanto, alguns vídeos notam que a população, outros setores do serviço público e até alguns profissionais de saúde conhecem insuficientemente o funcionamento do SUS. Conhecer o funcionamento do sistema de saúde seria uma condição relevante para efetuar, de fato, o direito à saúde. 
Em parte, as políticas públicas de saúde não são suficiente e adequadamente comunicadas à população, tampouco a educação em saúde tem espaço na formação escolar de nossas crianças e jovens. Por sua vez e em boa medida, os meios de comunicação desinformam sobre o SUS, mostrando com muita frequência apenas seus problemas e/ou insuficiências, o que aparece nas narrativas como dificuldade ao trabalho intersetorial de produção de saúde.

\section{CONCLUSÃO}

A produção dos vídeos de mídia tática por gestores e profissionais da RAPS paulistana operou em três dimensões complementares entre si. A primeira delas, no âmbito da intervenção formativa em que foram realizadas, concerne a uma estratégia de reflexão e de elaboração sobre algumas latitudes da produção de saúde nos territórios onde esses trabalhadores atuam: elaboração sobre o próprio trabalho e também acerca de possibilidades de potencializar suas ações por meio da composição com outros setores do serviço público e com atividades da comunidade local.

A segunda dimensão está ligada à questão midiática propriamente dita. Sob o universo das mídias digitais e das redes sociais, a elaboração dos vídeos e seu compartilhamento na WEB representam uma forma de entrar no debate público sobre a saúde mental e o SUS. Todos os vídeos indicam a adesão de seus autores aos princípios e objetivos das políticas públicas de saúde, sobretudo aquelas que definem o trabalho em rede e a visão de uma clínica ampliada e socialmente orientada para pensar e realizar os cuidados à saúde mental da população. Direta ou indiretamente, os autores defendem o direito à saúde e a necessidade de que os usuários do SUS e a população em geral apropriem-se e participem da produção e do cuidado à saúde.

A terceira dimensão que reponta dos vídeos decorre da anterior, ela tem a ver com a assunção do caráter multifacetado e complexo da saúde e do processo saúde/doença. Vários vídeos anunciam experiências, de fato, potentes de cuidado e/ou de produção de saúde, por meio vários meios: construção de vínculos sociais e afetivos positivos; intensificação da relação da comunidade com os espaços públicos; potencialização 
de encontros e da circulação social; usufruto do corpo e exercício da cidadania; e promoção da autonomia social.

Por fim, valorizar as referidas dimensões como produtoras de saúde não exclui os saberes profissionais e os aparatos tecnológicos da saúde, apenas os resitua no universo social mais amplo, a partir do qual a área da saúde em geral e da saúde mental em particular precisam estar abertas aos modos de vida da população, seus saberes, práticas, problemas e formas de tentar melhorar suas condições de vida e de saúde; o que parece ser, de fato, a condição de possibilidade da produção de saúde.

\section{REFERÊNCIAS}

ANA, W. P. S.; LEMOS, G. C. Metodologia científica: a pesquisa qualitativa nas visões de Lüdke e André. Revista Eletrônica Científica Ensino Interdisciplinar. Mossoró, v. 4, n. 12, 2018.

BRASIL. Ministério da Saúde. Portaria GM/MS 4.279, de 30 de dezembro de 2010, que estabelece Diretrizes para a organização da Rede de Atenção à Saúde no âmbito do Sistema Único de Saúde (SUS). Brasília: Ministério da Saúde, 2010.

BRASIL. Ministério da Saúde, Secretaria de Atenção à Saúde, Politica Nacional de Humanização da Atenção e Gestão do SUS. Clínica ampliada e compartilhada. Brasília, 2009.

CLINIO, A. A ação política no cotidiano: a mídia tática como conceito operacional para pesquisas em mídia, cotidiano e política. Revista Eletrônica do Programa de PósGraduação em Mídia e Cotidiano, v.1, n.1, abril 2013.

CURVO, D. R., MATOS, A. C. V., SOUZA, W. L., PAZ, A. C. A. Integralidade e clínica ampliada na promoção do direito à saúde das pessoas em situação de rua. Cadernos Brasileiros de Saúde Mental. Florianópolis, v.10, n.25, p.58-82, 2018.

GIL, A. C. Como elaborar projetos de pesquisa. 5. ed. São Paulo: Atlas, 2008. 
PEGORARO, R. F.; BASTOS, L. S. N. Experiências de acolhimento segundo profissionais de um centro de atenção psicossocial. Revista de Enfermagem e Atenção à Saúde, v. 6, n. 1, 2017.

SOUZA, L. A. P.; MENDES, V. L. O conceito de humanização na Política Nacional de Humanização (PNH). Interface - comunicação, saúde, educação, v. 13, p. 681-689. Botucatu, 2009.

TEIXEIRA, R. R. As redes de trabalho afetivo e a contribuição da saúde para a emergência de uma outra concepção de público. working-paper apresentado na Research Conference on: Rethinking "the Public" in Public Health: Neoliberalism, Structural Violence, and Epidemics of Inequality in Latin America Center for Iberian and Latin American Studies University of California, San Diego, 2004.

As dimensões da produção do comum e a saúde. Saúde e Sociedade, v.24, supl. I, p. 14-31. São Paulo: 2015.

\section{APÊNDICE - REFERÊNCIAS DE NOTA DE RODAPÉ}

8. Disponível em https://youtu.be/sUhKy4l-5q4

9.

Disponível em https://www.youtube.com/watch?v=8EKqOZPWmFw\&feature=youtu.be \&list=PLqCln B4_9098kjYxpXkqs4X1CroystxK

10. Disponível em https://youtu.be/nKJg57NJQo0

11. Disponível em https://youtu.be/JrgfJnu1eS4

12.

Disponível em

https://www.youtube.com/watch?v=E0_1RTouMk0\&feature=youtu.be 13.

https://www.youtube.com/watch?v=_9x_vVCIN6o\&feature=youtu.be 
14. Disponível em https://www.youtube.com/watch?v=HFJ0ICefFfs\&feature=youtu.be

15. Disponível em http://youtu.be/zdj7kj1n7hs

16.

Disponível

em

https://www.youtube.com/watch?v=_IAV2XqXJel\&feature=youtu.be

17. Disponível em https://youtu.be/3AbR_0ZLyn4

18.

Disponível

em

https://www.youtube.com/watch?v=uFJuqLZN8zl\&feature=youtu.be

19.

Disponível

em

https://www.youtube.com/watch?v=uZoW9tCa9ps\&feature=youtu.be

20.

Disponível

em

https://www.youtube.com/watch?v=9dKRfgk3Nu4\&feature=youtu.be

21.

Disponível

em

https://www.youtube.com/watch?v=vuEmtV76rqg\&feature=youtu.be

22.

Disponível

em

https://www.youtube.com/watch?v=aFHuRX3oXH8\&feature=youtu.b

23.

em https://www.youtube.com/watch?v=4JFPxveE_Mw\&amp=\&sns=em

24. Disponível em https://www.youtube.com/watch?v=a2hcV1 t0iao\&feature=youtu.be

25.

Disponível

em

https://www.youtube.com/watch?v=yUc15BRdho8\&feature=youtu.be

26. Disponível em http://youtu.be/PEh8hTxnZKQ

27.

Disponível

em

https://www.youtube.com/watch?v=u0Q1L5E5Wts\&feature=youtu.be 
28. Disponível em https://www.youtube.com/watch?v=DBu-_bq_ZHI

29.

Disponível

https://www.youtube.com/watch?v=iAwHWwNwQqE\&feature=youtu.be

30. Disponível em https://youtu.be/IFxVsBiCVtE

31. Disponível em https://youtu.be/xNKuazt0wJ8

32. Disponível em https://youtu.be/1p2ooyGTm-E

Enviado: Dezembro, 2019.

Aprovado: Dezembro, 2019. 